\title{
Challenges in developing a moisture metric to assess air change rates
}

\author{
Jalal Ahmed $^{\mathrm{a} *}$, Hector Altamirano-Medina ${ }^{\mathrm{a}}$, Dimitrios Rovas ${ }^{\mathrm{a}}$, Ian Mawditt ${ }^{\mathrm{b}}$ \\ a Institute for Environmental Design and Engineering, University College London, London, UK \\ b FourWalls, Bristol, UK
}

\begin{abstract}
Air change rates are difficult to measure in naturally ventilated buildings. There is incentive to develop alternative techniques to measure air change rates. Using a moisture metric is a possibility, but this is challenging as it requires the ability to quantify processes that affect the moisture balance in a room. This paper consolidates literature about how the moisture balance can be understood in field studies in terms of moisture generation, moisture buffering, and ventilation. Moisture generation rates have been reported in literature with some disparity. Moisture buffering is difficult to account for due to the complexity of the process in real buildings. Ventilation can be measured using tracer gas techniques, but these often provide a 'snapshot' of the air change rate which varies both spatially and temporally in buildings. However, a promising approach has been identified whereby moisture and ventilation conditions are examined over a longer period of time i.e. weeks.
\end{abstract}

Peer-review under the responsibility of the organizing committee of the ICMB21.

Keywords: moisture balance; moisture generation; moisure buffering; ventilation; air change rate

\section{Introduction/Background}

Ventilation is essential for indoor air quality and building fabric health. There are established tracer gas techniques to measure air change rates, but most of these methods provide a 'snapshot' of the air change rate over a short period of time. As air change rates can differ both spatially and temporally in buildings, capturing this dynamically changing variable is challenging. In addition, tracer gas techniques can be intrusive for occupants and expensive [1]. Therefore, there is incentive to develop cheaper, more invasive techniques to measure air change rates. Hygrothermal sensors are relatively cheap but using moisture (e.g. vapour pressure excess) as a metric for air change rates is challenging as it requires the ability to attribute moisture changes in a room to specific processes. Based on mass balance principles, it is theoretically possible to calculate the effect of one unknown process if all other processes are known. The aim of this paper is therefore to consolidate literature about how the moisture balance in a room can be understood in field studies and to discuss the implications of this for the development of a moisture-ventilation metric.

\section{Moisture Balance}

The moisture balance in a room is affected by several processes including internal moisture generation, ventilation, moisture buffering by materials, diffusion and condensation/evaporation. Under typical conditions, condensation is not a common occurrence in dwellings, and the impact of diffusion is considered insignificant enough that it can be ignored [2]. The remaining processes are discussed in the following sections.

\subsection{Moisture Generation}

Moisture is released indoors from people, pets, plants and occupant activities (e.g. cooking, showering). There have been many reports documenting moisture generation rates from different activities (e.g. [3], [4]), but rates for these activities can vary between studies because of differences in methods and conditions. Unfortunately, there can be difficulty in converting rates into a common unit as there is often a lack of contextual information. For example, [4] report a "typical" moisture generation rate of 1,500 grams per day from drying clothes indoors, whereas [5] report a family of four produces 11.97 litres ( 2,993 grams per person) of moisture from unvented clothes drying. Nonetheless, studies that have compiled moisture generation rates from different sources often show some agreement. In addition, there is an increasing amount of literature that has highlighted cultural differences in moisture generating activities (e.g. [6]) which may be important to consider in culturally diverse societies. With moisture generation rates for different activities in mind, surveys can be used to collect information about occupant activities allowing for a prediction of moisture generation per household [7].

\footnotetext{
* Corresponding author. E-mail: ucbqjah@ucl.ac.uk
} 


\subsection{Moisture Buffering}

Moisture buffering is the ability of materials in an indoor environment to moderate the indoor humidity level through adsorption and desorption processes. Several experimental methods have been proposed to characterise this based on the step response of a material to changes in relative humidity, e.g. Moisture Buffer Value [8]. However, as [9] comments, it is unclear how this could be applied to examine moisture buffering in real buildings which experience far more variable environmental conditions. In addition, real buildings have added complexities such as surface finishes (e.g. paints) which can reduce the moisture buffering performance of materials [10]. This means that without extensive hygrothermal modelling and testing, which is not viable in most field studies, there is difficulty inferring the impact of moisture buffering on changes to the moisture balance in a room.

\subsection{Ventilation}

The air change rate refers to the volume of air that has been exchanged between the indoors and outdoors. This rate is commonly described by the "air change per hour" parameter, which is the volume of air exchanged in one hour divided by the volume of a space. In naturally ventilated buildings, this is difficult to measure as air change rates vary both spatially and temporally [11]. Tracer gas techniques provide a 'snapshot' of the air change rate for a particular configuration (e.g. window position), particular weather conditions and a limited duration (up to hours). This means that capturing the dynamically changing air change rate in naturally ventilated buildings is not viable in most field studies. The exception to this is using the perfluorocarbon tracer technique, which allows the measurement of the average air change rate over longer time periods [12].

\section{Discussion and Conclusion}

Developing a method to use moisture as a metric for ventilation rates requires understanding how the moisture balance in a room changes due to the impact of internal moisture generation, moisture buffering and ventilation. Literature exists documenting moisture generation rates from occupants and activities. Along with a survey collecting occupant activity information, it is possible to estimate moisture generation rates per household [7]. On the other hand, moisture buffering is difficult to account for in field studies where hygroscopic materials are present. Air change rates can be measured on a timescale of hours using tracer gas techniques, but this can be expensive, intrusive, and highly complex if airflow between rooms needs to be considered.

However, it has been suggested that the impact of moisture buffering is reduced over longer timescales e.g. weeks [13]. If moisture conditions are assessed on this timescale, there are approaches to measure the average air change rate for the same period. One option is to calculate the air change rate from flow rates in mechanically ventilated dwellings. If the dwelling is airtight, then mechanical ventilation will be the prevailing contributor to air exchange instead of infiltration. A second approach is to measure the average air change rate using the perfluorocarbon tracer technique which captures the effect of both purpose-provided ventilation and infiltration. This approach looks promising as it has been used by [7] to examine the relationship between vapour pressure excess and the air change rate. However, there is a debate as to whether the average air change rate over a long period (e.g. weeks) is a useful metric for indoor air quality.

\section{References}

[1] J. Few and C. Elwell, "Measuring the ventilation rate in occupied buildings and adapting the CO2 tracer gas technique," in $40 t h$ AIVC Conference, 8th TightVent Conference, 6th Venticool Conference, 2019, pp. 517-526.

[2] ASHRAE, "Moisture management in buildings," in ASHRAE Handbook: Fundamentals, Atlanta, 2017.

[3] W. J. Angell and W. W. Olson, "Moisture Sources Associated with Potential Damage in Cold Climate Housing," 1988.

[4] BSI, "BS 5250:2011+A1:2016 Code of practice for control of condensation in buildings," 2011.

[5] A. T. Hansen, "Moisture problems in houses," Canadian Building Digest; no. CBD-231. National Research Council of Canada. Division of Building Research, 1984.

[6] F. W. H. Yik, P. S. K. Sat, and J. L. Niu, "Moisture generation through Chinese household activities," Indoor Built Environ., vol. 13, no. 2, pp. 115131, Apr. 2004.

[7] T. Kalamees, J. Vinha, and J. Kurnitski, "Indoor humidity loads and moisture production in lightweight timber-frame detached houses," J. Build. Phys., vol. 29, no. 3, pp. 219-246, 2006.

[8] C. Rode, R. H. Mortensen, L. H. Hansen, A. Ojanen, J. Svennberg, and J. Harderup, "Moisture Buffering of Building Materials," Technical University of Denmark DTU, 2006.

[9] V. Cascione, D. Maskell, A. Shea, and P. Walker, "A review of moisture buffering capacity: From laboratory testing to full-scale measurement," Construction and Building Materials, vol. 200. pp. 333-343, 10-Mar-2019.

[10] N. M. M. Ramos, J. M. P. Q. Delgado, and V. P. De Freitas, "Influence of finishing coatings on hygroscopic moisture buffering in building elements," Constr. Build. Mater., vol. 24, no. 12, pp. 2590-2597, Dec. 2010.

[11] A. K. Persily, "Field measurement of ventilation rates," Indoor Air, vol. 26, no. 1, pp. 97-111, 2016.

[12] R. N. Dietz, R. W. Goodrich, E. A. Cote, and R. F. Wieser, "Detailed description and performance of a passive perfluorocarbon tracer system for building ventilation and air exchange measurements," Meas. Air Leakage Build., pp. 203-264, 1986.

[13] S. V Glass and A. Tenwolde, "Review of moisture balance models for residential indoor humidity," 12th Can. Conf. Build. Sci. Technol., pp. 231-246, 2009. 